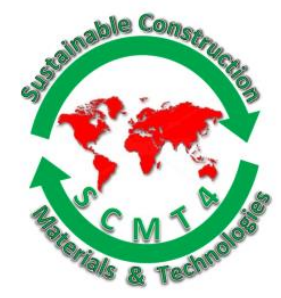

SCMT4

Las Vegas, USA, August 7-11, 2016

\title{
SEACON: Redefining Sustainable Concrete
}

\author{
S. Khatibmasjedi ${ }^{1 \mathrm{a}}, \mathrm{F}^{*}$. De Caso ${ }^{1 \mathrm{~b}}$, and A. Nanni ${ }^{1 \mathrm{c}}$ \\ ${ }^{1}$ Dept., Civil, Architectural and Environmental Engineering, University of Miami. \\ ${ }^{1 a}$ Email: <mortezakhatib@umiami.edu>, ${ }^{1 b}$ Email: 〈f.decasoybasalo@umiami.edu>, \\ ${ }^{1 c}$ Email: nanni@miami.edu>.
}

\begin{abstract}
Concrete is the second most consumed material on earth, after freshwater. The World Meteorological Organization estimates insufficiency of drinking water for over half of the world's population by 2025. Yet, the construction industry uses several billion tons of freshwater annually to wash aggregates and produce concrete. Thus, a significant step to redefine sustainability in concrete is to substitute, when possible, the use of freshwater with saltwater for concrete production. Furthermore, accelerating sustainable concrete can be achieved by considering changes in the aggregates and cement; for example recycled concrete aggregate (RCA) even when contaminated with chlorides from years of exposures, represents an ideal replacement for natural fine and coarse aggregates. More importantly, the leap to redefine sustainable concrete can happen when reconsidering the chloride content levels in cement, which will result in the ability to burn solid wastes as fuel (co-generation) and utilize byproducts of clinker production such as cement kiln dust, which is hazardous waste.
\end{abstract}

This paper presents partial results of a larger study aiming at demonstrating the safe utilization of SEACON: a concrete made from seawater and/or salt-contaminated aggregates (natural or recycled) to redefine sustainability in concrete production. Evidently, due to the high chloride content of seawater and saltcontaminated aggregates, its use in reinforced concrete (RC) is prohibited by building codes due to corrosion of the steel reinforcement. Redefining sustainable concrete with SEACON requires the use of alternative noncorrosive reinforcement material technologies, such as Glass-Fiber-Reinforced-Polymer (GFRP) bars or stainless steel. New findings validating the viability of SEACON for a sustainable concrete production when combined with noncorrosive reinforcement to construct durable and economical concrete infrastructures are presented herein. To this end, two SEACON mixes compared to a concrete mix made with traditional constituents were exposed to different environments for up to one year and evaluated through material mechanical characterization tests. Based on the initial findings, one of the SEACON mixes was selected for further validation tests, in which fresh and hardened concrete and durability properties are evaluated.

\section{INTRODUCTION}

This paper has a twofold objective: firstly, engage stakeholders in the civil engineering industry by introducing a potentially disruptive technology that redefines sustainability in concrete production: SEACON, a concrete made from seawater and/or salt-contaminated aggregates (natural or recycled), 
coupled with noncorrosive reinforcement to construct durable and economical concrete infrastructures. Secondly, summarize initial results validating the viability of SEACON, and present new findings of an ongoing project that aims at confirming with experimental work that the presence of chlorides is not deleterious to the fresh and hardened properties of plain concrete, nor concrete reinforced with noncorrosive Glass-Fiber-Reinforced-Polymer (GFRP) or stainless steel bars.

Water in Concrete. Potable water is used directly as a constituent of the concrete mix, as well as indirectly in concrete-related activities including: washing, saturating aggregates, curing, equipment cleaning...etc. A life cycle analysis of freshwater for the amount consumed in concrete construction is alarming: freshwater withdrawals have tripled over the last 50 years due to rapid growth of world population, and continue to grow. These considerations require an all-inclusive construction industry approach to rethink sustainable concrete production alternatives, where current steps such as lean thinking (reducing unnecessary waste of freshwater) have not made a significant impact. A paradigm shift is required.

Seawater is an abundant, convenient and cost-effective alternative, especially in coastal areas. Despite the distinct sustainable advantages, the use of seawater in concrete is currently prohibited. The main reason is early corrosion of steel reinforcement (rebars) due to the presence of chlorides in seawater. This also affects the early stages of hydration and workability of Portland cement, and the long-term development of strength, with potential risk of promoting alkali-aggregate reactions with susceptible aggregate (Neville, 2001). Concerning fresh concrete properties, some studies have suggested that the use of appropriate chemical admixtures can lead to proper workability of concrete mixed with seawater (Kaushik and Islam, 1995). Furthermore, the influence of seawater in concrete as part of the mix design is negligible after 20 years. Additionally, existing research has shown that salt in seawater has no significant negative effects on the properties of fresh and hardened concrete even when poor-quality aggregates are used (Hime, 2007); where the strength of the concrete mixed with seawater is typically higher than that with freshwater in the initial stages of curing; then, the difference of strength after the long-term curing based on the mixing water, becomes small. Promising outcomes have been achieved when mineral admixtures, such as blast furnace slag, are added to the concrete mix design (Fukute et al., 1990).

Recycled Concrete Aggregate (RCA). Concrete, asphalt and masonry represent about $23 \%$ of the total US construction and demolition waste, ranging from 250 to 300 million tons, and end in increasingly problematic landfills. Unless recycled, the yearly accumulation of these waste products could cause significant economic and environmental problems. While the scarcity of natural aggregates increases, the use of RCA from demolished structures represent a sustainable opportunity in the production of concrete mitigating the need for landfill space and new aggregate quarries (Vázquez, 2012). The use of RCA in concrete is not new, it initiated decades ago for non-structural applications such as fill material and base course material in road construction. RCA is less dense, more porous, and has higher water absorption than natural aggregate, since its properties are affected by the residual adhered mortar (McNeil and Kang, 2013).

In spite of lower quality, large scale testing has shown that RCA can still be used to create structural concrete when properly designed. Factors influencing the properties of concrete with RCA include: the quality and amounts of the cement adhered to the original aggregate; the interfacial transition zone between them; the percentage replacement of natural aggregate with RCA; and, the mixing procedure (Vázquez, 2012, Poon et al., 2004). Since the porosity of RCA is about twice that of ordinary concrete (GómezSoberón, 2002) rebars in an RCA concrete are more susceptible to attack from aggressive chemicals such as sulphates and chlorides or other types of degradation, resulting in accelerated corrosion. Furthermore, since the qualities of RCA are highly varied among different sources, there is concern about high chlorides content in RCA obtained from the demolition of structures that have been subjected to chloride penetration; assuming a noncorrosive reinforcement is used in RCA-based concrete, RCA would then become especially attractive in transportation infrastructure when demolition of (salt-contaminated) old structures and subsequent reconstruction is required. 
SEACON. The project SEACON aims at demonstrating the safe utilization of seawater and salt contaminated aggregates (natural or recycled) for a sustainable concrete production when combined with noncorrosive reinforcement to construct durable and economical concrete infrastructures. SEACON is a 2.5-year project funded under the aegis of Infravation, 'an infrastructure innovation programme' which address the challenges identified in the European Commission's White Paper on Transport: Smart, Green and Integrated transport; with the objective of enabling a high quality infrastructure offering high service levels to the user/economy/society through solutions for both new and existing infrastructure.

SEACON has been started by a consortium of six partners and three collaborators led by the University of Miami, and its culmination will be two real-size demonstration projects in two countries (Italy and Florida, USA), at locations with very different (micro) climates (continental away from the coastline and subtropical along the coastline), addressing two different infrastructure elements (reinforced concrete retaining wall and bridge superstructure, the Halls River bridge). These demonstrations represent critical elements of the transportation infrastructure and will provide the opportunity for long-term monitoring.

SEACON Phase I - One Year Exposure. To initially evaluate the independent effect of chloridecontaminated components (seawater and RCA) in a concrete mix, cylinder specimens made from three different mixes (summarized in Table 1, phase I) namely A, B and C, were produced: A) a traditional concrete mix containing Portland cement, fly ash, natural-coarse-aggregates, sand and tap-water, an airentraining admixture, a water reducing admixture and workability-retaining admixture. B) Proportions identical to mix A, except for the substitution of tap water with seawater from Key Biscayne Bay, Florida. C) Contains seawater from Key Biscayne Bay and the natural-coarse-aggregate of mix A was substituted with RCA. Miami Olite and waste obtained from the demolition of a bridge in Ohio with a nominal maximum aggregate size of $25 \mathrm{~mm}$ ( 1 in.) were used as the natural-coarse-aggregates and RCA, respectively. The maximum and nominal size of the aggregates were the same, where the distribution for all mixes was equivalent. Therefore differences among the three mixes in fresh and hardened concrete should not be attributed to the particle size. Mix A and B are very similar in quantities, while mix C has a higher amount of coarse aggregates with respect to the other two mixes due to the specific gravity of RCA.

For each mixture, fresh concrete properties were evaluated under standard laboratory conditions, as well as hardened concrete properties in terms of compressive and tensile split strength using cylindrical $100 \mathrm{~mm}$ (4 in.) diameter specimens at early age and after exposure in aging environments including immersion in seawater (SW), a tidal range (BK) and a tropical 'control' condition (CC) environment in Miami, Florida as shown in Figure 1. Results showed that when replacing seawater and/or RCA in a concrete mix, no significant changes to the fresh or early hardened concrete properties (up to 28 days) were evident; nor degradation caused by the ageing environments (Selicato and Moro, 2015). New findings from one-year exposure to seawater (SW) and control condition (CC) validate the viability of SEACON for a sustainable concrete production, while new test specimens are produced to evaluate and substantiate the combination of SEACON with noncorrosive reinforcement as presented herein. New results will be released upon completion of one year exposure to the tidal range.

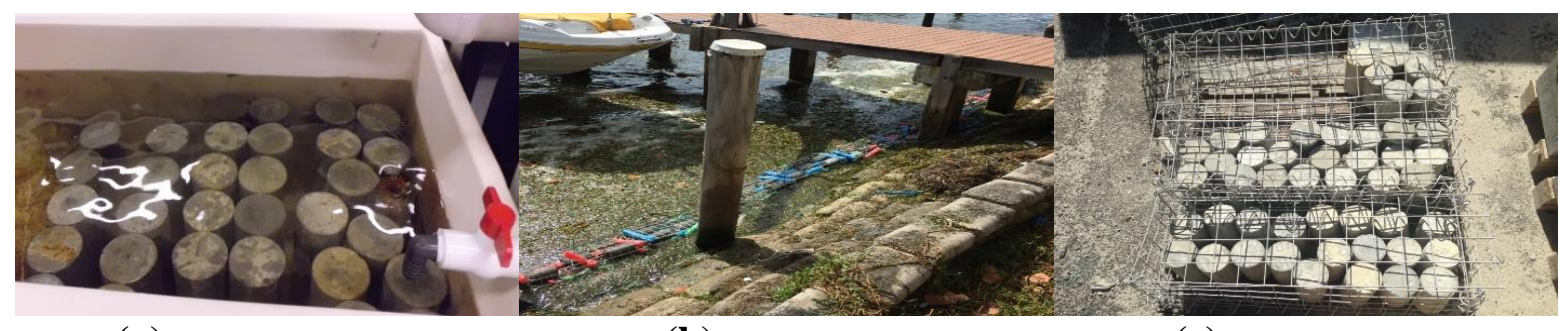

(a)

(b)

(c)

Figure 1. Aging Environments: Immersion in Seawater (a), Tidal Range (b) and Control Condition (c) 


\section{EXPERIMENTAL PLAN}

The aim of the SEACON phase II (an ongoing activity) is to: i) compare laboratory accelerated aging with actual field conditions; and ii) confirm the compatibility and durability of the tensile and bond properties of a representative noncorrosive rebar embedded in SEACON and exposed to the accelerated aging environments. To this end the concrete mix design per the requirements of Florida Department of Transportation (FDOT) for the culminating real-size demonstration project at the Halls River Bridge was used. The effect of seawater substitution in concrete was studied based on the initial SEACON findings (Selicato and Moro, 2015). Hence modified mixes A' and B' were made as reflected in Table 1, which Error! Reference source not found.shows FDOT regular Type IV concrete mix (A') and the SEACON $\operatorname{mix}\left(B^{\prime}\right)$.

Table 1. Concrete Mix Constituents and Proportions

\begin{tabular}{|c|c|c|c|c|c|c|}
\hline \multirow{2}{*}{ Mixture } & \multirow{2}{*}{ Units } & \multicolumn{3}{|c|}{ Phase I } & \multicolumn{2}{|c|}{ Phase II } \\
\hline & & $\operatorname{mix} \mathbf{A}$ & $\operatorname{mix} B$ & $\operatorname{mix} \mathbf{C}$ & $\operatorname{mix} A^{\prime}$ & $\operatorname{mix} \mathbf{B}^{\prime}$ \\
\hline Portland cement (type II) per ASTM C 150 & \multirow{7}{*}{$\mathrm{kg} / \mathrm{m}^{3}$} & 297 & 297 & 297 & 332 & 332 \\
\hline Fly ash (class F) per ASTM C 618 & & 77 & 77 & 77 & 83 & 83 \\
\hline Tap water & & 161 & - & - & 168 & - \\
\hline Seawater & & - & 161 & 161 & - & 168 \\
\hline Silica Sand & & 813 & 813 & 813 & 612 & 612 \\
\hline NA - Coarse aggregate \#57 & & 927 & 927 & - & 1038 & 1038 \\
\hline RCA & & - & - & 963 & - & - \\
\hline Water reducer (BASF GL 7500) & \multirow{3}{*}{$\mathrm{mL} / \mathrm{m}^{3}$} & 731 & 731 & 731 & - & - \\
\hline Set retarding (BASF 961r) & & 2071 & 2071 & 2071 & 814 & 814 \\
\hline Air-entraining (BASF AE 90) & & 19 & 19 & 19 & 8 & 8 \\
\hline Water-binder (w/b) ratio & - & 0.43 & 0.43 & 0.43 & 0.40 & 0.40 \\
\hline
\end{tabular}

Note: $1 \mathrm{~kg} / \mathrm{m}^{3}=1.685 \mathrm{lb} . / \mathrm{yd}^{3}$ and $1 \mathrm{~mL} / \mathrm{m}^{3}=0.0258 \mathrm{fl} . \mathrm{oz} / \mathrm{yd} \mathrm{d}^{3}$

The experimental tests for each batch of fresh concrete, conducted during each casting, included the slump in accordance with ASTM C 143; density in accordance with ASTM C138; and air content in accordance with ASTM C 231. The properties of hardened concrete were evaluated through mechanical tests to determine compressive strength per ASTM C39, and split tensile strength per ASTM C496. To this end, concrete cylinder specimens with dimensions of $100 \times 200 \mathrm{~mm}(4.0 \times 8.0$ in.) were made for each mix. Specimens were cured in a wet chamber at an average temperature of $23^{\circ} \mathrm{C}\left(73^{\circ} \mathrm{F}\right)$ and $\mathrm{RH}$ of $100 \%$, for 28 days. Compression and split tension tests were conducted at 3, 7, and 28 days with three specimen repetitions.

SEACON Phase II - Concrete Durability. The validation of SEACON mix design, meeting the requirements of FDOT Halls River bridge project includes five experimental components: i) compressive and tensile strength properties post accelerating aging exposure; ii) sulfate attack evaluation; iii) alkali silica reaction (ASR) evaluation; iv) shrinkage evaluation; and v) carbonation and salt crystallization evaluation. Each experiment component is described in further detail below.

i) Compressive and tensile strength: cylinder specimens made of both mixes will be tested for the compression and split tension properties of hardened concrete after $6,12,18$, and 24 months post accelerated aging exposure, fully submersed in tanks containing constantly circulating seawater at $60^{\circ} \mathrm{C}$ from Key Biscayne Bay. Simultaneously, specimens will be exposed to regular subtropical weather in Miami, Florida, this environment serves as a control benchmark for comparison purposes. 
ii) Sulphate attack: Hydrated cement paste cubes will be tested by an accelerated test method proposed by Monteiro et al. (2000). 24 cubes with the dimension of $12.7 \mathrm{~mm}(0.5 \mathrm{in})$ will be cast from each mixture. Compressive strength of half of the specimens will be tested after 7 days curing and remaining specimens will be submerged in 4 percent $\mathrm{Na}_{2} \mathrm{SO}_{4}$ solution maintained at a $\mathrm{pH}$ of 7.2. The 28-day strength of those samples will be compared to the initial 7-day strength and scanning electron microscopy (SEM) analysis will be also conducted on specimens collected from split tension test cylinders to evaluate the sulphate attack.

iii) Alkali silica reaction (ASR): Prisms with the dimension of $100 \times 100 \times 285 \mathrm{~mm}(4 \times 4 \times 11.5$ in) were cast and will be tested by modified Concrete Prism Test (CPT) per ASTM C1293. Petrographic examination of the concrete prisms will be conducted after the test using practice ASTM C856.

iv) Shrinkage: Length change of $25 \times 25 \times 290 \mathrm{~mm}$ (1x1x11.5 in) mortar bars will be monitored per ASTM C157. The length change of 3 prisms from each mixture will be monitored every 3 month for 2 years.

v) Carbonation and salt crystallization: Samples collected from split tension test cylinders will be analyzed with SEM to evaluate and determine the level of carbonation and salt crystallization.

SEACON Phase II - Characterization of GFRP rebars. Redefining sustainable concrete with SEACON requires the use of alternative noncorrosive reinforcement material technologies, such as Glass-FiberReinforced-Polymer (GFRP) rebars. To this end, the second part of SEACON phase II involves the characterization and validation to couple GFRP rebars with SEACON. This includes three experimental components: i) physio-mechanical benchmark GFRP rebar properties; ii) GFRP rebar durability properties and accelerating aging correlation; and iii) GFRP rebar bond to concrete. Each experiment component is described in further detail below.

i) GFRP physio-mechanical benchmark properties: Control (un-aged) 10-mm diameter GFRP rebar (nominal \#3 size) will be tested to determine benchmark properties of a selected GFRP as summarized in Table 2. Figure 2.a, shows the cross-section and surface of the selected GFRP rebar. The smaller rebar size was selected since it can be assumed that any potential mechanical degradation in GFRP rebar caused by SEACON will become more apparent in a smaller size rebar.

ii) Durability properties: GFRP rebars were embedded in concrete beam specimens made from the phase II SEACON mixes (A' and B') with dimensions of 150x190x1420 mm (6x7.5x56 in.) as seen in Figure 2.b. The specimen beam cross section was designed in order to replicate the bulkhead cap test samples that will be constructed for durability monitoring and correlation of accelerated tests to field conditions at the Halls River Bridge (real-size demonstration of the SEACON project in Florida, United States). Each beam specimen was reinforced with four \#5 GFRP bars, where the embedded rebars will be extracted from the beam at 6, 12, 18 and 24 months after exposure to standard ambient (outdoor) and accelerated conditioning immersed in seawater at $60^{\circ} \mathrm{C}\left(140^{\circ} \mathrm{F}\right)$. The accelerated aged rebars will then be tested per the physio-mechanical properties summarized in Table 2. Furthermore, accelerated aged results will be compared with future field durability rebar test results from the Halls River bridge samples, this will provide the necessary experimental information to correlate and model the long-term durability properties of the GFRP rebar based on the Arrehenius model (Bank et al., 2003).

iii) Bond to concrete: The relative bond between the GFRP rebar and concrete by pullout testing will be experimentally determined per the ACI440.3R, B.3. 200-mm (8 in.) concrete cubes with the embedded \#3 GFRP rebar as shown in Figure 2.c, were cast and will be aged under the same exposure as the beam specimens aforementioned. Three tests of relative bond will be conducted at 6, 12, 18 and 24 months after exposure. In addition, SEM image analysis will be performed at two distinctive locations including the GFRP rebar resin-fiber interface; and the concrete-GFRP rebar surface interface. 
Table 2. Test Methods to Determine the GFRP Rebar Properties

\begin{tabular}{|l|c|l|}
\hline \multicolumn{1}{|c|}{ GFRP Property } & \multicolumn{1}{c|}{$\begin{array}{c}\text { Test } \\
\text { Standard }\end{array}$} & \multicolumn{1}{c|}{ Comments } \\
\hline a) Cross-sectional area & ASTM D792 & $\begin{array}{l}\text { Measured cross-sectional area will be determined and } \\
\text { compared to nominal rebar sizes }\end{array}$ \\
\hline b) Tensile properties & ASTM D7205 & $\begin{array}{l}\text { Ultimate load, strength, modulus and strain will be } \\
\text { computed }\end{array}$ \\
\hline $\begin{array}{l}\text { c) Transverse shear } \\
\text { strength }\end{array}$ & ASTM D7617 & $\begin{array}{l}\text { Transverse shear strength based on nominal and measured } \\
\text { cross-sectional areas will be computed }\end{array}$ \\
\hline d) Fiber content & ASTM D2584 & Fiber content based on weight by burn off method. \\
\hline $\begin{array}{l}\text { e) Moisture absorption / } \\
\text { mass change }\end{array}$ & ASTM D570 & $\begin{array}{l}\text { Short term (24hrs) and long term (saturation) absorption } \\
\text { levels at standard laboratory conditions }\end{array}$ \\
\hline $\begin{array}{l}\text { f) Horizontal shear } \\
\text { strength }\end{array}$ & ASTM D4475 & $\begin{array}{l}\text { Standard Test Method for Apparent Horizontal Shear } \\
\text { Strength of Pultruded Reinforced Plastic Rods By the } \\
\text { Short-Beam Method }\end{array}$ \\
\hline $\begin{array}{l}\text { g) Microstructure } \\
\text { observation }\end{array}$ & SEM & $\begin{array}{l}\text { Visual characterization of the cross-section of GFRP } \\
\text { rebars }\end{array}$ \\
\hline
\end{tabular}

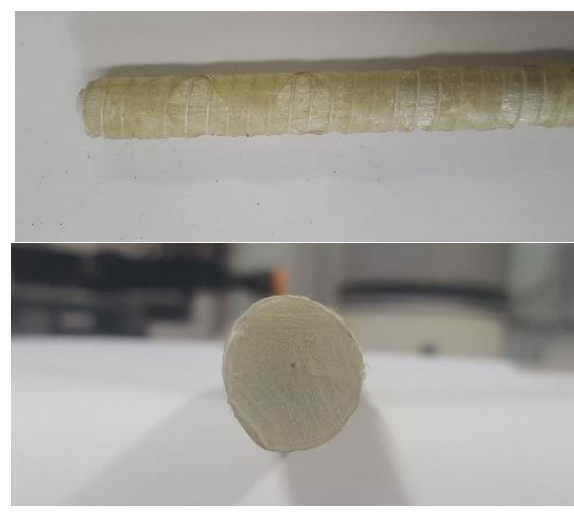

(a)

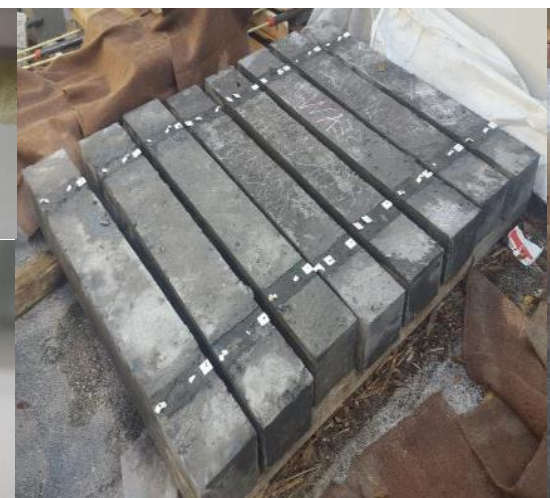

(b)

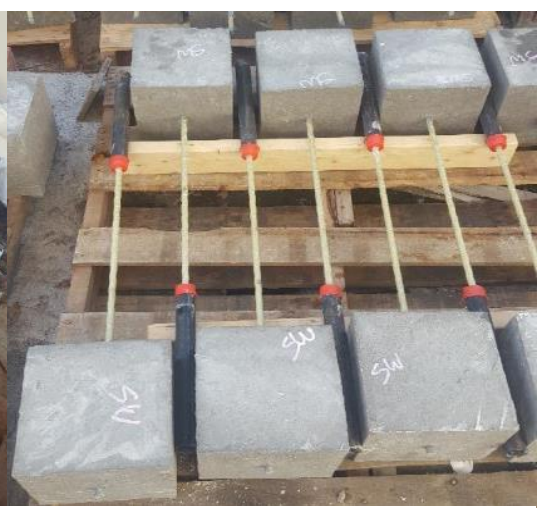

(c)

Figure 2. Surface and Cross Section of the selected GFRP bar (a), Beam Specimens for Durability Evaluation (b), and Pullout Test Specimens (c)

\section{RESULTS \& DISCUSSION}

SEACON Phase I - One Year Exposure. SEACON phase I specimens reached one year of exposure to the aging environments previously described except tidal range, where new test results from the compressive and split tensile strength of each mix were evaluated and summarized in Table 3 . Time versus strength graphs are provided in Figure 3, where the solid line represents the control aging environment $(\mathrm{CC})$, and the dash line immersion in seawater $(\mathrm{SW})$.

The increase in compressive strength with respect to time for all three concrete mixes (A, B and C) was comparable, reaching a peak of approximately $60 \mathrm{MPa}$. When compared to the laboratory 28 day control test, mix A and B had similar percentages increases, confirming that replacing tap water with seawater does not change the compressive properties of concrete. On the other hand, mix $\mathrm{C}$ had the highest percentage increase, and the highest rate of increase in compressive strength as seen in Table 3 and Figure 3.a, respectively. This may be attributed to the RCA properties. Since RCA has a greater absorption coefficient there might have been a higher amount of water stored inside the concrete. This water may have been released from the aggregates to the cement paste causing further hydration after the initial 28 days. At a 
year exposure it may be too early to determine the effects caused by ageing exposures, since no degradation was detected.

The split tensile strength after a year of exposure also increased for all mixes, with no apparent degradation for mix B and C compare to the control mix (A) or benchmark valuesError! Reference source not found.. On the other hand the rate of increase of the tensile split strength varied for the mix type and exposure environment, as seen in Figure 3.b. There is explanation for these changes, and further tests are needed at a later stage to define the projection of the split tensile strength, and define the trend.

Table 3. Compressive and Split Tensile Strength up to 1 Year for Different Environments (Average value and STD based on 3 replicates) Note: $1 \mathrm{MPa}=145 \mathrm{psi}$

\begin{tabular}{|c|c|c|c|c|c|c|c|c|c|c|}
\hline \multirow[b]{2}{*}{ Env. } & \multirow[b]{2}{*}{$\begin{array}{c}\text { Age } \\
\text { (days) }\end{array}$} & \multicolumn{3}{|c|}{ Mix A } & \multicolumn{3}{|c|}{ Mix B } & \multicolumn{3}{|c|}{ Mix C } \\
\hline & & $\begin{array}{c}\text { Average } \\
\text { strength } \\
(\mathrm{MPa})\end{array}$ & $\begin{array}{l}\text { STD } \\
(\mathrm{MPa})\end{array}$ & $\begin{array}{l}\text { Change } \\
\text { with } \\
\text { respect to } \\
28\end{array}$ & $\begin{array}{c}\text { Average } \\
\text { strength }\end{array}$ & $\begin{array}{l}\text { STD } \\
(\mathrm{MPa})\end{array}$ & $\begin{array}{l}\text { Change } \\
\text { with } \\
\text { respect } \\
\text { to } 28\end{array}$ & $\begin{array}{c}\text { Average } \\
\text { strength } \\
(\mathrm{MPa})\end{array}$ & $\begin{array}{c}\text { STD } \\
(\mathrm{MPa})\end{array}$ & $\begin{array}{c}\text { Change } \\
\text { with } \\
\text { respect } \\
\text { to } 28\end{array}$ \\
\hline \multicolumn{11}{|c|}{ Compression Test Results } \\
\hline $\mathbf{n} / \mathbf{a}$ & 28 & 53.6 & 1.80 & - & 50.9 & 1.99 & - & 44.8 & 1.53 & - \\
\hline \multirow[b]{2}{*}{$\mathrm{CC}$} & 56 & 59.2 & 2.33 & $+10.5 \%$ & 55.9 & 1.91 & $+10.0 \%$ & 52.1 & 4 & $+16.3 \%$ \\
\hline & $\begin{array}{c}84 \\
393\end{array}$ & $\begin{array}{l}58.6 \\
59.6\end{array}$ & $\begin{array}{l}1.82 \\
4.41\end{array}$ & $\begin{array}{l}+9.3 \% \\
+11.2 \%\end{array}$ & $\begin{array}{l}56.8 \\
60.3\end{array}$ & $\begin{array}{l}1.99 \\
4.39\end{array}$ & $\begin{array}{l}+11.7 \% \\
+18.5 \%\end{array}$ & $\begin{array}{l}54.3 \\
60.2\end{array}$ & $\begin{array}{c}5 \\
0.41\end{array}$ & $\begin{array}{l}+21.2 \% \\
+34.4 \%\end{array}$ \\
\hline \multirow[b]{2}{*}{ SW } & 56 & 54.0 & 2.27 & $+0.8 \%$ & 51.3 & 2.20 & $+0.9 \%$ & 48 & 6.24 & $+7.1 \%$ \\
\hline & $\begin{array}{c}84 \\
393\end{array}$ & $\begin{array}{l}56.6 \\
56.6\end{array}$ & $\begin{array}{l}3.54 \\
2.72\end{array}$ & $\begin{array}{l}+5.6 \% \\
+5.6 \%\end{array}$ & $\begin{array}{l}53.3 \\
59.9\end{array}$ & $\begin{array}{l}0.70 \\
5.19\end{array}$ & $\begin{array}{c}+4.9 \% \\
+17.7 \%\end{array}$ & $\begin{array}{l}49.3 \\
61.7\end{array}$ & $\begin{array}{l}4.08 \\
2.15\end{array}$ & $\begin{array}{c}+10.04 \% \\
+37.7 \%\end{array}$ \\
\hline \multicolumn{11}{|c|}{ Split Test Results } \\
\hline $\mathbf{n} / \mathbf{a}$ & 28 & 4.1 & 0.22 & - & 4.1 & 0.25 & - & 4.0 & 0.38 & - \\
\hline $\mathrm{CC}$ & $\begin{array}{c}56 \\
393\end{array}$ & $\begin{array}{l}3.9 \\
4.6\end{array}$ & $\begin{array}{l}0.18 \\
0.52\end{array}$ & $\begin{array}{c}-4.6 \% \\
+12.2 \%\end{array}$ & $\begin{array}{l}4.1 \\
4.4\end{array}$ & $\begin{array}{l}0.16 \\
0.17\end{array}$ & $\begin{array}{l}-0.5 \% \\
+7.3 \%\end{array}$ & $\begin{array}{l}4.0 \\
5.2\end{array}$ & $\begin{array}{l}0.96 \\
0.32\end{array}$ & $\begin{array}{l}-0.4 \% \\
+30 \%\end{array}$ \\
\hline SW & $\begin{array}{c}56 \\
393\end{array}$ & $\begin{array}{l}4.2 \\
5.5\end{array}$ & $\begin{array}{l}0.20 \\
0.78\end{array}$ & $\begin{array}{l}+2.6 \% \\
+34.1 \%\end{array}$ & $\begin{array}{l}4.0 \\
4.5\end{array}$ & $\begin{array}{l}0.19 \\
0.66\end{array}$ & $\begin{array}{l}-1.4 \% \\
+9.8 \%\end{array}$ & $\begin{array}{l}3.8 \\
4.3\end{array}$ & $\begin{array}{l}0.67 \\
0.22\end{array}$ & $\begin{array}{l}-5.0 \% \\
+7.5 \%\end{array}$ \\
\hline
\end{tabular}




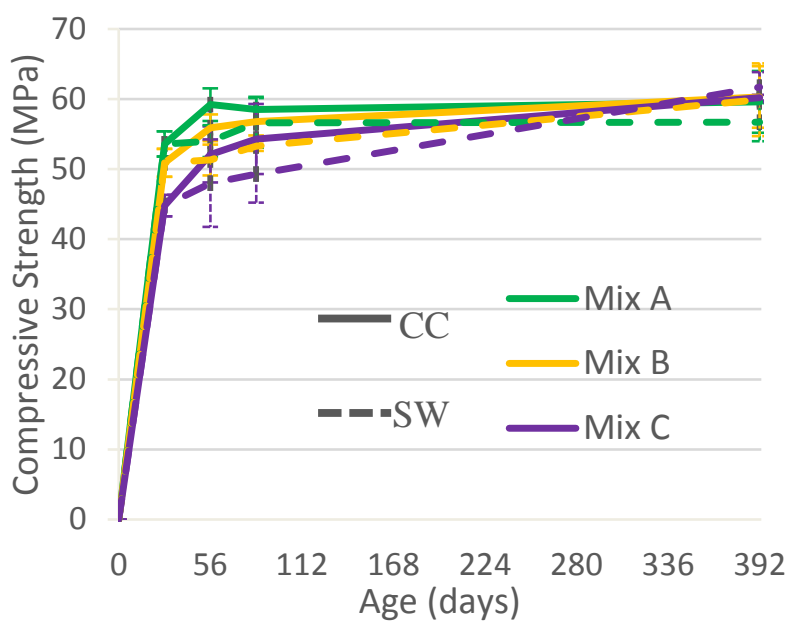

(a)

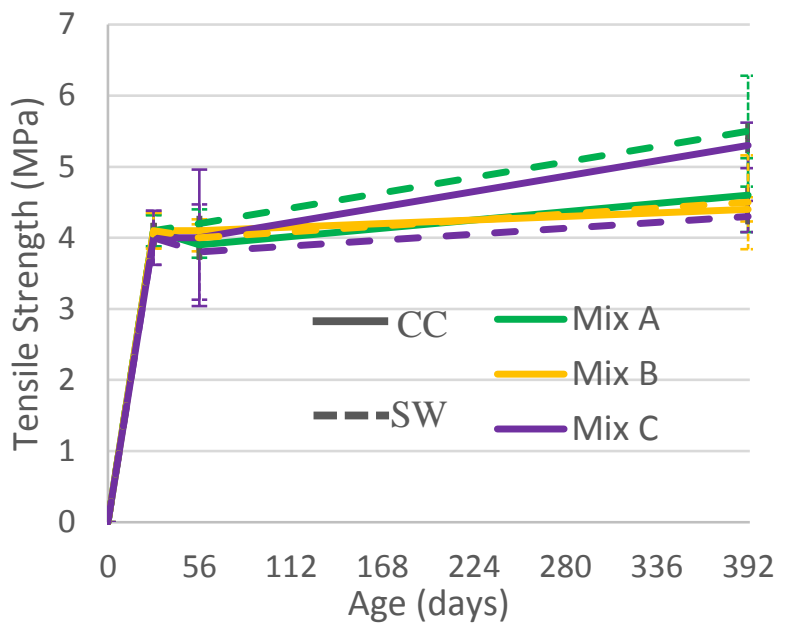

(b)

Figure 3. Compressive (a) and Tensile (b) Strength Development for Different Environments up to 1 year exposure for Phase I mixes.

SEACON Phase II - Concrete Durability. The early age concrete mixes results have been completed including fresh and hardened properties, as summarized in Table 4 and 5, respectively. Overall, no differences in the fresh properties between mix A' and B' were measured, which indicates that seawater does not significantly affect the behavior of fresh concrete. The air content in all mix designs was intentionally low, in fact the dosage of air entraining admixture used was primarily aimed at controlling workability of the mix rather than improving the freeze-thaw resistance of the concrete. The results for the air content show the lower average value of $1 \%$ corresponding to mix B' which could be related to the incompatibility between seawater and air entraining agent. It has been observed during mixing process that more air-entraining agent is needed for seawater concrete to get to the desired air content.

The results for the early compression and split tension tests of concrete up to the 28 day curing period are presented in Figure 4, while average and standard deviation values are summarized in Table 5. The compressive and split tensile strength development over time observed in both mixes followed what it is typically expected. The differences in strength at the 28 day curing period are comparable for both mix designs. The findings validate SEACON phase I results, where acceleration in the development of strength is typically observed in presence of chlorides in the short term. Accelerated aging tests continue and upon completion of the 6 month period, new results will be released.

Table 4. Fresh Concrete Characterization

\begin{tabular}{|c|c|c|c|c|}
\hline \multirow{2}{*}{ Mixture type } & $\begin{array}{c}\text { Slump and } \\
\text { STD }\end{array}$ & $\begin{array}{c}\text { Density and } \\
\text { STD }\end{array}$ & $\begin{array}{c}\text { Air Content and } \\
\text { STD }\end{array}$ & $\begin{array}{c}\text { Concrete temperature } \\
\text { and STD }\end{array}$ \\
\cline { 2 - 5 } & $(\mathbf{c m .})$ & $\left(\mathbf{k g} / \mathbf{m}^{\mathbf{3}}\right)$ & $(\boldsymbol{\%})$ & $\left({ }^{\circ} \mathbf{C}\right)$ \\
\hline Mix A' & $10(0.40)$ & $2349.9(0.53)$ & $1.3(0.31)$ & $26(0.91)$ \\
\hline Mix B' & $10(0.56)$ & $2358.6(0.30)$ & $1.0(0.11)$ & $26(0.80)$ \\
\hline
\end{tabular}

Note: $1 \mathrm{~kg} / \mathrm{m}^{3}=1.685 \mathrm{lb} / \mathrm{yd}^{3}, 1 \mathrm{~cm}=0.4 \mathrm{in}$. 
Table 5. Compressive and Split Tensile Strength up to 28 days

\begin{tabular}{|c|c|c|c|c|}
\hline \multirow[b]{2}{*}{$\begin{array}{l}\text { Age } \\
\text { (days) }\end{array}$} & \multicolumn{2}{|c|}{ Mix $A^{\prime}$} & \multicolumn{2}{|c|}{ Mix B' } \\
\hline & $\begin{array}{c}\text { Compression \& STD } \\
\text { (MPa) }\end{array}$ & $\begin{array}{c}\text { Tension \& STD } \\
(\mathrm{MPa})\end{array}$ & $\begin{array}{c}\text { Compression \& STD } \\
\text { (MPa) }\end{array}$ & $\begin{array}{c}\text { Tension \& STD } \\
\text { (MPa) }\end{array}$ \\
\hline 3 & $40.13(1.7)$ & $2.95(0.5)$ & $41.58(3.4)$ & $3.4(0.2)$ \\
\hline 7 & 42.79 (1.7) & $3.8(0.06)$ & $45.32(1.03)$ & $3.64(0.2)$ \\
\hline 28 & $57.3(1.8)$ & $4(0.50)$ & $56.9(2.10)$ & $4.1(0.30)$ \\
\hline
\end{tabular}

Note: $1 M P a=145$ psi

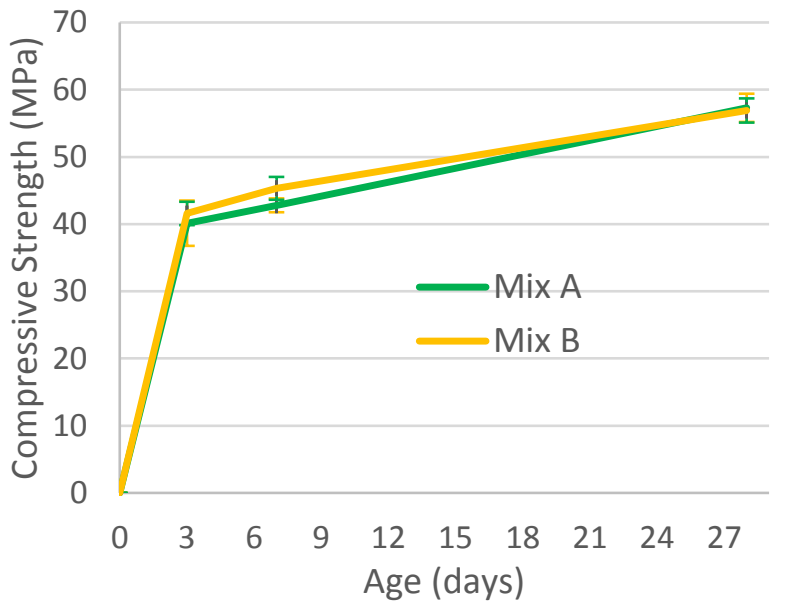

(a)

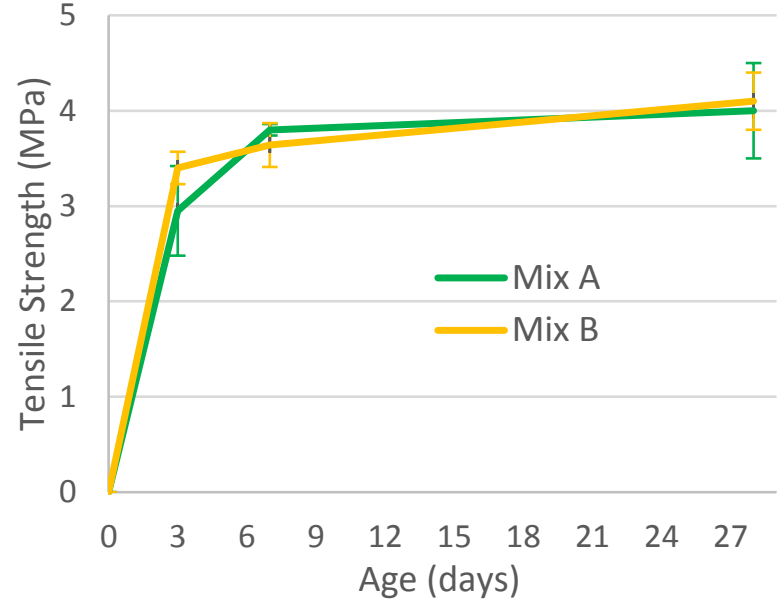

(b)

Figure 4. Compressive (a) and Split Tensile (b) Strength Development up to 28 days

\section{CONCLUSION}

This paper engages stakeholders in the civil engineering industry by introducing a potentially disruptive technology that redefines sustainability in concrete production: SEACON, a concrete made from seawater and/or salt-contaminated aggregates (natural or recycled), coupled with noncorrosive reinforcement to construct durable and economical concrete infrastructures. Ongoing SEACON activities described herein include compressive and split tensile strength test results of concrete made with seawater and/or RCA, which after the first year confirming that replacing tap water with seawater does not change the properties of concrete. Durability observations on specimens submerged in seawater up to a year also showed no degradation caused by the use of seawater in concrete; while the RCA mix had a significant higher increase in strength after exposure, compared to the other mixes

Additionally, ongoing tests to validate the viability of SEACON, were presented and confirm that the presence of chlorides is not deleterious to the fresh and hardened properties of plain concrete. Furthermore, durability tests on plain and GFRP-reinforced SEACON specimens initiated with the overarching objective to compare and correlate the laboratory accelerated aging results from specimens submerged in seawater at $60^{\circ} \mathrm{C}\left(140^{\circ} \mathrm{F}\right)$ for $6,12,18$ and 24 months, to actual field conditions using replicate durability test specimens that will form part of the bulkhead cap construction per FDOT requirements of the real-size demonstration of the SEACON project in Florida, United States: the Halls River Bridge. Also, durability validation to couple GFRP rebars with SEACON is underway with numerous experimental tests to determine the physiomechanical and bond to concrete properties of a selected GFRP rebar. Although the results provided herein are early evaluations, they are indicative that SEACON can redefine sustainability in concrete production. 


\section{ACKNOWLEDGMENTS}

The authors gratefully acknowledge:

a) contributions of the personnel at the Pennsuco Plant of Titan Cement Group for the advice, cooperation and permission to use their facilities;

b) National Science Foundation (NSF) for the support provided to the Industry/University Center for Integration of Composites into Infrastructure (CICI) at the University of Miami under grant NSF IIP-1439543; and

c) Infravation program under grant $31109806.005-S E A C O N$.

Any opinions, findings, and conclusions or recommendations expressed in this material are those of the authors and do not necessarily reflect the views of the supporting agencies.

\section{REFERENCES}

BANK, L. C., GENTRY, T. R., THOMPSON, B. P. \& RUSSELL, J. S. 2003. A model specification for FRP composites for civil engineering structures. Construction and Building Materials, 17, 405-437.

FUKUTE, T., YAMAMOTO, K. \& HAMADA, H. 1990. Study on the Durability of Concrete Mixed with Sea water. Report of the Port and Harbour Research Institute, 29.

GÓMEZ-SOBERÓN, J. M. 2002. Porosity of recycled concrete with substitution of recycled concrete aggregate: an experimental study. Cement and concrete research, 32, 1301-1311.

HIME, W. G. 2007. Alkalies, Chlorides, Seawater, and ASR. Concrete International, 29.

KAUSHIK, S. \& ISLAM, S. 1995. Suitability of sea water for mixing structural concrete exposed to a marine environment. Cement and Concrete Composites, 17, 177-185.

MCNEIL, K. \& KANG, T. H.-K. 2013. Recycled concrete aggregates: A review. International Journal of Concrete Structures and Materials, 7, 61-69.

MONTEIRO, P. J., ROESLER, J., KURTIS, K. E. \& HARVEY, J. 2000. Accelerated test for measuring sulfate resistance of hydraulic cements for Caltrans LLPRS program. University of California, Berkeley, 510, 643-8251.

NEVILLE, A. 2001. Seawater in the mixture. Concrete international, 23, 48-51.

POON, C., SHUI, Z., LAM, L., FOK, H. \& KOU, S. 2004. Influence of moisture states of natural and recycled aggregates on the slump and compressive strength of concrete. Cement and Concrete Research, 34, 31-36.

SELICATO, F. \& MORO, M. I. 2015. Effects Of Seawater And Chloride-Contaminated Recycled Concrete Aggregates On Reinforced Concrete Properties. Thesis, University of Miami.

VÁZQUEZ, E. 2012. Progress of Recycling in the Built Environment: Final Report of the RILEM Technical Committee 217-PRE, Springer Science \& Business Media. 